nios duran más de lo que pudieran anhelar los contrincantes. No hay más envidia en un escritor hacia su colega que en un gerente de una casa comercial por el de la firma competidora.

Pero además, y esto es lo importante, la gente de letras no se une porque no tiene para qué unirse. Se concibe que se junten once hombres para golpear una pelota, porque si no se juntan once de cada lado, el juego no obtiene cierto rango especial y no logra despertar interés en el público. Pero ¿para qué necesita unirse un novelista con otro novelista? Uno escribe un libro y lo publica, si puede (es decir, si tiene un editor amigo). El otro lo observa de reojo, y en cuanto puede lo imita. No es que sean enemigos ni que se deseen mal. Es que su trabajo es individual hasta la exageración y no hay casi manera de hacerlo colectivo. Las asociaciones de escritores para producir literatura son generalmente transitorias, y cuando son duraderas, lo común es que se trate de hermanos. Hoy mismo los hermanos Tharaud en Francia y los Alvarez Quintero en España prueban lo que digo. Se rre dirá que fuera de la faena misma de escribir libros, los escritores tienen o pueden tener otros deberes. Es la verdad. Allí comienza su error de mantener el individualismo, indispensable para la creación artística, cuando ya no tiene razón de ser y hasta es perjudicial al tratar otros negocios.

Los sindicatos profesionales tienen un papel definido en la marcha de la sociedad: defienden los intereses de cada uno de sus componentes y usan para esa defensa el arma más eficaz, que es la unión. Los escritores deberían unirse en sindicatos de la misma manera que hacen otros grupos sociales. En su trato con editores - tanto de publicaciones periódicas como de libros-, los escritores necesitan defensa. La dispersión es evidentemente la culpable de que el trabajo intelectual sea remunerado hoy en Chile con menos esplendidez que en otros tiempos y que en realidad descienda a ojos vistas. Es también el origen de muchos otros daños que sería prolijo enumerar y que darían a este artículo dimensiones más pavorosas que las que ya tiene.-R A ÚL SILVA CASTRO.

\title{
Las novelas de Januario Espinosa
}

7 ANUARIO Espinosa es de los pocos escritores chilenos (2) que ha perseverado en una labor continua y honorable. Pertenece a una generación que produjo los mejores cuentistas chilenos. De su época es Santiván, que ha callado por mucho tiempo. Conoció a Federico Gana, a Baldomero Li- 
1lo; y tuvo sus coqueteos tolstoyanos en dîas memorables. Desde 1905 , en que obtiene un premio en un concurso abierto por la Revista Zig-Zag, pasando por 1907, en que publica la primera novela (Cecilia), hasta la actualidad, su obra literaria sigue un desarrollo perfectamente parejo. Es un escritor honrado, que domina los procedimientos seguros de la observación y deja un conjunto de obras muy apreciables. No se eleva a la gran emoción, salvo en la deliciosa novela Cecilia (1907); pero tampoco desciende al mal gusto. Su chilenidad de cepa acendrada le da un sentido exacto de la proporción, un tono de mesura que no traiciona al escritor, no obstante su autodidactismo espiritual.

La gente de la clase media, el mundo oscuro y sórdido de los telegrafistas con dos preccupaciones centrales: el am or y la bebida, son observados con ojo malicioso y fino por Espinosa. No idealiza nunca a sus personajes ni pretende elevarlos hacia la estilización. Viven, aman y mueren oscuramente. Siguen sus instintos primarios y se aferran a la materialidad de la vida. Jamás una exaltación idílica; rara vez un profundo destello de espiritualidad. El novelista se pasea por entre estas gentes con destreza y maneja sus resortes vitales con mano segura. Aparecen, de vez en cuando, algunas ironías, un toque rápido de malicia, una segunda intención disimulada por el trazo nervioso. Quizá ningún escritor chileno ha conseguido representar mejor a la genuina clase media provinciana $y$, sobre todo, a las gentes de Linares y de Copiapó. Es digno de nota el hecho de que en los últimos años, con el evidente avance de la vida, con las facilidades abiertas for el progreso, la clase meaila ha perdido su matiz característico. La riqueza íntima de su fisonomía ya no se sorprende en la abierta entrega con que la cogió el autor de Cecilia y de La señorita Cortés Monroy (1928).

La clase nedia - el siútico según la jerga santiaguina - tiene sus reservas espirituales y su colorido churrigueresco que muy bien han visto Espinosa, Maluenda en Venidos a menos y Barrios en Lo que niega la vida. Hoy día la clase media ha evolucionado en lo político y en lo social. Un tipo común de mobiliario ha standardizado sus gustos, y el automóvil y el fonógrafo han enriquecido sus emociones. Las casas provincianas con muebles rojos, grandes lámparas de petróleo y un piano cubierto de chucherías forman el decorado del mundo que pinta Espinosa.

Su interés en la literatura chilena consiste en el arraigo que ha tenido su clase dentro de su mente literaria. Pero Espinosa, junto con afinarse literariamente, no incurre en el mal gusto 
propio de sus congéneres. Se liberta, como escritor, de todo barroquismo y, al parecer, por deliberado propósito se afirma en una actitud angulosa y en un estilo seco, directo y poco dado a las galas.

En Cecilia se percibe admirablemente el carácter narrativo de la obra de Espinosa.

Rompe el libro con naturalidad y fuerza:

Nací en Rari. Es este un villorrio de una veintena de casas, que se alínean al borde de un estero, cuyas aguas son claras y tranquilas. Desde allí se divisan perfectamente las casas del balneario Panimávida y su parque adyacente.

Rara vez Espinosa se sale de esta tranquila indiferencia ante el paisaje admirable que rodea a Linares. Un desgano natural o una indiferencia absoluta son su reacción sensitiva ante la naturaleza pletórica de esas regiones.

Cecilia es un tipo de novela semi-idílica y semi-realista. No alcanza a obtener su éxito por las situaciones dramáticas o por la energía de la narración. Su mérito consiste, al revés, en lo que insinúa, en lo que deja de decir, en todo aquello que suponemos. Una fina maestría de narrador, un dominio seguro de la técnica la deja como una isla espléndida en una serie de novelas opacas. No ha vuelto Espinosa a producir nada más preñado de sugestiones. Su producción moderna, que algunos consideran inferior a esta primera obra, tiene menos gracia.

En el arte debe existir algo de misterio y exaltación que levante el relato. La carencia de tales condiciones enerva la narración y la confunde con la pintura desmañada. Espinosa reveló en Cecilia un dominio cabal de la novela y justificó las esperanzas que se pusieron en su talento. La vida humilde no añade grandes aportes a lo que había logrado con su libro primerizo.

Volvemos a encontrar las típicas cualidades de Espinosa en Las inquietudes de Ana María (1916). En esta novela, muy agradable y liviana, Espinosa nos presenta un problema reiterado en las letras chilenas: el joven de la clase media que conquista el afecto de una niña de la aristocracia. El motivo es ingrato y es un tema que han manoseado innumerables autores. Desde Martín Rivas, pasando por $U n$ idilio muevo, hasta Desarraigados de Millán Iriarte, los novelistas chilenos han prodigado este asunto. Sólo Espinosa, a mi ver, ha salvado felizmente la dificultad del tema. Los amores de Ana María con Moisés, el administrador de su fundo, terminan en el matrimonio. La novela es rica de observación y agrada por la sencilla inaestría de siu desenvolvimiento. 
No hay deslumbramiento ni cursileria ante la clase alta. El autor se sabe recatar y contener ante estos latifundistas que pinta y juzga con cierta ironía corrosiva, pero sin plebeyo desborde. Aquí revela Espinosa su mejor calidad de novelista y su ojo certero. Espinosa representa el buen sentido linarense, la socarronería del centro-sur, en presencia de estos terratenientes altivos y dominados por una ideología finchada. En su novela asistimos perfectamente a la reacción producida en la sensibilidad de la clase media, que comienzia a sentir sus derechos y su fuerza, ante la oligarquía santiaguina con feudos en Colchagua y en toda la zona céntrica de Chile.

El Moisés de Januario Espinosa se parece un poco al héroe de Santiván en $E l$ crisol. Como él es rudo y fuerte de carácter, como él ha leído libros anarquistas y humanitaristas, como él ha enriquecicio el carácter en duras proezas atléticas. Santiván y Januario Espinosa tienen una conciencia de clase algo política, pero antes que nada literaria. Ambos son aficionados a estas intrigas tomadas de las viejas novelas francesas de Feuillet y del Felipe Derblay de Ohnet. Claro es que ambos escritores criollos mejoran el ambiente y no incurren en el mal gusto del segundo de esos novelistas franceses. Cuando se escriba la historia de la novela en Chile habrá que rastrear el origen de esta tendencia que comenzaron hombres de la clase alta chilena en pleno siglo XIX y que tuvo tanto éxito hasta hace poco tiempo.

Las inquietudes de Ana María, como casi todas las obras de Espinosa, no tiene gran atmósfera. El estilo es sinple y correcto, pero con poco relieve. El admirable paisaje del Sur sólo está esbozado por breves pinceladas. La pintura del ambiente elegante sólo se insinúa. La prosa no es rica. Antes bien, desnutrida y opaca.

Sin embargo, creer os que Cecilia y Las inquietudes de Ana 1aría representan el mejor período artístico de Januario Esinosa. Un soplo fresco y sano circula por sus páginas y un ideasmo temperado contrasta con el último lote de obras suyas, donde el telégrafo y sus empleados levantan todos sus defectos y la sordidez anínica más dolorosa.

Desde 1916 hasta. 1927 Espinosa se aleja de la producción activa. En 1928 aparece La señorita Cortés Monroy. Es una novela extensa, con hermosos y poéticos títulos de capítulos. Es admirable el sentido artístico que logra Espinosa allí; fero el contenido de la obra está muy lejano de tal enúnciación poética. Los empleados de telégrafos que pinta Espinosa no tienen idealismo. Son minúsculos, socarrones y sensuales. Sus vidas están 
ligadas a un oscuro destino. Los problemas que absorken sus almas son terreros y vulgares. Viven en permanente chismografía y otean a los vecinos desde sus observatorios de comadrejas. El alcohol y el sexo los abruman. Parece de repente que un deseo de liberación los exaltara; pero ... nada ocurre. Sólo se trasladan a un «botiquín» o picantería para beber chicha o mosto. Se yergue a ratos un hombre que toma un andar nietzscheano, pero todo su destino se disuelve en un potrillo colmado de alcohol.

Muy bien dado el ambiente ínfimo, minúsculo de esta gente. El lector, no obstante, desearía librarlos del pesado fardo de esos destinos y quisiera ver un vuelo en medio de tanta miseria. La protagonista, la señorita Cortés Monroy, que tiene tensas las inquietudes de algunos telegrafistas, acaba en una vulgar ramera, que se entrega sórdidamente.

Con todos los defectos anotados, Espinosa consigue pintar un mundo sombrío y alcohólico, en qué hombres y mujeres viven precariamente. Nadie ha conseguido, entre nosotros, coger esa abatida porción de la existencia chilena provinciana.

A medida que Espinosa avanza en cultura, su estilo se enjuta. Es curioso este caso literario. Otros, con las nuevas influencias (la de Proust es ejemplar) abandonan su manera antigua y procuran desprenderse de los méritos tradicionales. Espinosa, en cambio, se hace más áspero, más seco. Así lo vemos en su reciente obra $U n$ viaje con el diablo. El primer relato, que da el nombre al libro, es muy curioso. Está lleno de intención y de picardía, pero cuando promete más interés, el viaje termina... y el diablo se fuga.

En La caída del titán Espinosa torna a pintar la clase media provinciana y consigue interesar con un relato de buena ley. En Morse y el amor existe agrado y fluidez de relato. El resto del libro es insignificante con relación a la honrada lakor de Espinosa. Espinosa aquí trata de simplificar su estilo en tal forma que se acerca a lo telegráfico. Abundan mucho también las escenas de cantina, los causeos, la reiterada nota del chileno subalterno. La entidad de su obra antigua y la simpatía humana de Espinosa exigen que vuelva por sus fueros de novelista. Es un hombre sobrio, con nervio, que está dotado de excelentes facultades para la novela. Esperamos de su madurez espiritual una obra que lo libre de la pesadumbre de este reiterado ambiente de telegrafistas. El ancho mundo, con sus vastos temas, invita a mejores asuntos. Aun creemos que el autor de Cecilia y de Las inquietudes de Ana María recupere su brio antiguo y nos entregue una sorpresa de creación.-R I C A R D O A. LA T C H A M. 